\title{
Una aproximación a las relaciones interculturales en escuelas secundarias de Villa Lugano, a partir del análisis de las representaciones sociales hacia población de origen boliviano en Buenos Aires (2015-2018)
}

\author{
An approach to intercultural relations in Villa Lugano's High Schools, \\ based on the analysis of social representations about bolivian inmigrants \\ in Buenos Aires (2015-2018). \\ Gisele Kleidermacher \\ Dra. Ciencias Sociales \\ Facultad de Ciencias Sociales. Universidad de Buenos Aires \\ CONICET - Instituto de Investigaciones Gino Germani \\ kleidermacher@gmail.com \\ Darío Lanzetta \\ Facultad de Ciencias Sociales. Universidad de Buenos Aires \\ CONICET - Instituto de Investigaciones Gino Germani \\ dario_lanzetta@hotmail.com
}

\begin{abstract}
Resumen
En el presente escrito nos proponemos analizar las relaciones interculturales que se producen en las aulas de escuelas de educación media de gestión estatal en Villa Lugano, barrio ubicado en el sur-oeste de la Ciudad Autónoma de Buenos Aires. Para ello hemos aplicado un cuestionario estructurado, compuesto por preguntas abiertas, preguntas cerradas y escalogramas que nos han permitido analizar en mayor profundidad las representaciones sociales que los alumnos de 14 a 16 años asistentes a dichas escuelas, producen acerca de diversas nacionalidades migrantes, así como de los vínculos en el aula y el rol de la escuela en el tratamiento de la discriminación y la migración. Presentamos los resultados para la nacionalidad boliviana, para la cual hemos construido categorías de análisis de acuerdo con la Teoría Fundamentada, entendiendo que estas representaciones dificultan la construcción de relaciones interculturales intra-áulicas.
\end{abstract}

Palabras Clave: Relaciones Interculturales, Representaciones Sociales, Migraciones, Educación

\begin{abstract}
This article analyzes the intercultural relations that take place in public high schools of Villa Lugano neighborhood, located in the south-west of the Autonomous City of Buenos Aires.For this purpose, we used a quantitative technique, based on a structured questionnaire, composed of open questions, closed questions and scalograms that have allowed us to analyze in greater depth the social representations that the
\end{abstract}

Gisele Kleidermacher · Darío Lanzetta

Una aproximación a las relaciones interculturales en escuelas secundarias de Villa Lugano,

a partir del análisis de las representaciones sociales hacia población de origen boliviano en Buenos Aires (2015-2018).

Autoctonía. Revista de Ciencias Sociales e Historia, Vol. III, N²2, Julio-Diciembre 2019, 132-158

ISSN 0719-8213

DOI: http://doi.org/10.23854/autoc.v3i2.135 
students of 14 to 16 years attending these schools, produce about different migrant nationalities. We also analyze the role of the school in the treatment of discrimination and migration. We present the results for the Bolivian nationality, for which we have constructed categories of analysis according to the Grounded Theory, understanding that these representations hinder the construction of classroom intercultural relations.

Keywords: Intercultural Relations, Social Representations, Migrations, Education

Recibido: 28 de Mayo de 2019 • Aceptado: 10 de Julio de 2019

\section{Introducción}

El presente artículo se enmarca en la temática migratoria desde una perspectiva sociológica. Particularmente aborda las representaciones sociales que estudiantes de tres escuelas públicas de nivel medio del barrio de Villa Lugano, cuyas modalidades de especialización difieren en orientación, (re) construyen acerca de un colectivo migratorio, partiendo del supuesto que dichos actores se encuentran atravesados por los discursos que circulan al interior de la institución escolar. Los datos han sido construidos en el marco de un Proyecto de Reconocimiento Institucional con sede en la Facultad de Ciencias Sociales, Universidad de Buenos Aires, en el que participamos. Cabe advertir que si bien en dicho proyecto nos propusimos como objetivo caracterizar las representaciones sociales que construyen los jóvenes de 14 a 16 años de escuelas públicas del barrio mencionado acerca de cinco colectivos migrantes y nacionales: asiáticos, paraguayos, bolivianos, africanos y argentinos; aquí sólo analizaremos aquellas que refieren a la población de origen boliviano․

Por su parte, la elección del barrio se definió luego de explorar registros poblacionales e identificar la gran presencia de migrantes en las comunas 1 y 8 (INDEC, 2012) ${ }^{2}$. De este modo, quedó originalmente definido que trabajaríamos con escuelas de Villa Lugano, Villa Soldati, Constitución y Nueva Pompeya, todas ellas ubicadas en la Comuna 8 de la Ciudad Autónoma de Buenos Aires. Sin embargo, las adversidades encontradas en la entrada al campo ${ }^{3}$ nos llevaron a decidir trabajar solo en las escuelas de la localidad de Villa Lugano.

La propuesta de indagar en los discursos que circulan dentro de la institución escolar tiene como base no sólo nuestro interés por las representaciones sociales que se construyen en un ámbito primordial de socialización para cada uno de los sujetos involucrados sino, más concretamente, por el impacto que puede tener esta mirada 
constituyente y performativa de la "otredad" sobre los vínculos que se establecen, y así para la integración o segregación de las comunidades, tanto al interior de la institución como por fuera de sus muros, esto es, a nivel general. Partiendo entonces del supuesto de que ésta es una de las instituciones a través de las cuales el Estado implementa políticas para administrar la diversidad étnica desde un rol socializador, focalizamos en aquellas representaciones de los/ as jóvenes que a ella asisten, pues son uno de los actores que las producen, reproducen y actualizan. En este sentido, cabe advertir a modo introductorio, que vamos a interpretar a las representaciones sociales como "miradas" acerca de la alteridad que están presentes en el discurso que construyen los jóvenes estudiantes que han sido escolarizados y han sido atravesados por las representaciones escolares en tanto discurso de la institución.

En el marco de los proyectos de investigación en los que venimos trabajando desde hace ya varios años, hemos desarrollado distintos documentos de trabajo (Malegarie y Lanzetta, 2012, 2013; Gonza y Lanzetta, 2011) en los que debatimos respecto de la idea de que la escuela reproduce el imaginario social que la rodea; es decir, que la institución escolar se ve permeada por los procesos sociales de discriminación y prejuicio que atraviesan sus prácticas pedagógicas, sus discursos y sus reglas de interacción, construyendo representaciones sociales también discriminatorias al interior de las puertas de las escuelas, constituyéndose como escenarios en donde se expresan aquellas visiones presentes en la sociedad civil respecto de la diversidad étnica.

Tanto nuestra investigación como el presente artículo se centran en analizar el fenómeno migratorio desde la perspectiva que tiene como eje la dinámica de interacción entre grupos inmigrados y la población residente. En este sentido, el trabajo que venimos realizando y que aquí compartimos se centra en producir distintos resultados que, a nuestro juicio, contribuyen a enriquecer el campo de estudios de las relaciones interculturales entre nativos y migrantes, y específicamente en torno a las representaciones sociales que los primeros construyen de los segundos, e indaga acerca de las dinámicas de interacción presentes en la institución educativa, con foco en las representaciones sociales que caracterizan o definen un "nosotros" y un "otros".

De esta forma, el presente escrito, abocado al ámbito de las relaciones interculturales en las escuelas, se estructura del siguiente modo: en primer lugar, presentamos la perspectiva teórica desde la cual entendemos las relaciones interculturales y las representaciones sociales. En segundo lugar, exponemos los aspectos metodológicos donde se plantea la forma en que fueron construidos y analizados los datos. En un tercer apartado se presentan los resultados, a partir de gráficos, y se analizan las representaciones construidas para, finalmente, presentar las conclusiones del estudio. 


\section{Relaciones interculturales y representacio- nes sociales}

En relación a la elección de la Escuela Media para llevar a cabo la investigación, tal como fue explicitado en la introducción de este trabajo, consideramos que se trata de un espacio privilegiado para analizar las representaciones sociales que allí se construyen, por el impacto que puede tener esta mirada constituyente y performativa de la "otredad" para la integración o segregación de las comunidades a nivel general, al entender dicho espacio educativo como ámbito socializador por excelencia siendo una de las instituciones del Estado que gestionan la diversidad. La escuela lleva adelante importantes acciones socializadoras en niños y adolescentes, naturalizando y promoviendo determinados criterios morales de verdad y de deber ser. Sin embargo, a través del presente estudio y mediante el abordaje propuesto, consideramos necesario correr a los estudiantes del rol pasivo, en tanto que meros receptores de políticas y reproductores de discursos y representaciones que circulan en la sociedad civil y las instituciones del Estado, para asignarles un rol interpelador y activo en la producción de representaciones y discursos sociales respecto a las actuales migraciones sur-sur.

Partimos de entender que, frente a los flujos migratorios motorizados como resultado del sistema capitalista, los Estados administran mediante la ejecución de políticas la diversidad étnica y cultural. Asimismo, en el marco regio- nal, dentro del Mercosur se ha avanzado considerablemente en las legislaciones migratorias e incluso los flujos poblacionales intrarregionales presentan una curva en ascenso, sobre todo para Argentina. La política migratoria argentina ha ido presentando significativos logros en los últimos años, sobre todo en la ampliación de derechos y ciudadanía a extranjeros que residen en el país (Novick, 2010), y si bien ello constituye el puntapié inicial hacia la integración regional, no evita que persistan distancias estructurales en las percepciones sobre el otro, lo que refuerza la necesidad de repensar la integración desde los estratos jóvenes de la población.

En este sentido, Cohen (2009) advierte respecto del rol activo que el Estado desempeña en el tratamiento de la diversidad a través de sus instituciones. Si bien lo hacen desde roles diferentes, la Escuela, la Justicia y las Fuerzas de Seguridad comparten la posibilidad de implementar estrategias de relación entre nativos y migrantes, basadas en un código moral hegemónico (Benhabib, 2005) portador de una fuerte y homogénea carga cultural que penaliza y excluye a ciertos colectivos de migrantes a partir de su origen etno-nacional. La idea de código moral hegemónico refiere a la supuesta existencia de una comunidad nacional integrada, homogénea y homogeneizante, portadora de una "naturaleza moral unificada" (Benhabib, 2005). Este código, entendido como estrategia que desde la sociedad receptora se emplea para licuar la diversidad, funciona como criterio de exclusión, como fron- 
tera delimitadora de un nosotros nacional y un otros excluido, extraño. En el caso argentino, el código moral hegemónico ha estado históricamente poblado de imágenes estigmatizadoras del extranjero que alertan sobre el potencial peligro de las relaciones interculturales para la integridad de la identidad nacional (Cohen, 2009).

García Canclini nos propone que la adopción de la noción de interculturalidad debe ser entendida en su análisis como "la confrontación y el entrelazamiento" que sucede cuando los grupos entran en relaciones e intercambios, e "implica que los diferentes son lo que son en relaciones de negociación, conflicto y préstamos recíprocos" (2004: 15). La premisa central de estos estudios es analizar las relaciones que se producen entre una sociedad mayor y las minorías que la componen, entendiendo que las mismas son relaciones conflictivas, en diversos casos asimétricas y que ello debe modificarse mediante diversas políticas. A modo de ejemplo, valga nombrar el trabajo de Ferrão Candau (2010), quien busca dar a conocer y discutir las tensiones presentes en el desarrollo de la educación intercultural en América Latina.

Siendo a través de las representaciones sociales de los estudiantes la manera de abordar en nuestro proyecto las relaciones interculturales en el espacio institucional educativo, proponemos entenderlas de acuerdo con la visión de Moscovici (1986), quien las define como constructos cognitivos compartidos en la interacción social cotidiana que proveen a los individuos de un entendimiento de sentido común de sus experiencias en el mundo. Dentro del campo de la psicología social, Jodelet (1986) distingue dos fuentes determinantes para la emergencia de las representaciones sociales: por una parte, la determinación social central (se refiere precisamente a las condiciones socioeconómicas o históricas en una sociedad, las cuales influyen en las representaciones sociales en cuanto a su extensión, evolución e interacción); y por otra parte, la determinación social lateral (referida a la influencia que ejerce el grupo en el condicionamiento de la representación social en que el sujeto individual también deja su impronta). Enfatiza, además, sobre el carácter funcional de las mismas, ya que se orientan hacia la práctica.

En la misma línea, Jean Claude Abric (1994) señala que las representaciones funcionan como un sistema duradero de interpretación de la realidad que rige las relaciones entre los individuos con su entorno físico y social, ya que determinará sus comportamientos o sus prácticas. Se erigen como guías para la acción y no resultan un mero reflejo de la realidad, sino que en su constitución diversos factores concurren y le dan significación, factores contingentes y factores sociales: el contexto social e ideológico, el lugar del individuo en la organización social, la historia del individuo y del grupo, los desafíos sociales, etc. "Visión funcional del mundo que permite al individuo o grupo conferir sentido a sus conductas y entender la realidad mediante su propio 
sistema de referencias, y adaptar y definir de este modo un lugar para sí” (Abric, 1994: 11).

Interpretar las representaciones en términos de miradas sobre la alteridad implica ubicar el eje del análisis en un lugar que nos permita comprender la interacción y las prácticas sociales interculturales. Entendidas de este modo, se constituyen como mediadoras de la acción, y, por lo tanto, en un elemento indispensable para pensar qué tipos de vínculos son los que estas miradas habilitan y cuáles obstruyen.

Nos proponemos entonces desentrañar el contenido de las representaciones sociales que los jóvenes de las escuelas secundarias de gestión pública de Villa Lugano construyen sobre sujetos de origen boliviano, para, de esta forma, contribuir al análisis de las relaciones interculturales que se producen en las aulas. No desconocemos los estudios acerca del rol de los docentes en las prácticas interculturales, sin embargo, el objeto aquí es otro: focalizar en los propios estudiantes, en su visión sobre un grupo migratorio, $\mathrm{y}$ sobre el rol que la escuela tiene en el tratamiento de estos temas.

\section{Aspectos metodológicos}

El propósito del presente apartado es poner de manifiesto cuál ha sido la estrategia teórico-metodológica implementada, con el fin de evidenciar y dar sustento a los resultados que aquí se presentan, teniendo en cuenta que trabajamos con representaciones sociales desde un enfoque cuantitativo.

Tal como afirman Cea D’Ancona y Valles (2010), investigadores que estudian la temática que aquí nos convoca, estas representaciones no suelen ser expresadas, o bien, lo hacen de un modo solapado mediante eufemismos que esconden juicios valorativos. Algunos autores atribuyen este hecho a los cambios en la exteriorización de las representaciones discriminatorias hacia los grupos minoritarios. Entre ellos, Sergio Caggiano (2008), especializado en el análisis de procesos migratorios de países limítrofes hacia la Argentina y las relaciones y representaciones que sobre ellos se construyen en los medios masivos de comunicación, observa que la adhesión a normas sociales "democráticas e igualitarias" características de las sociedades occidentales modernas, han hecho que la discriminación étnica no esté "bien vista" o no sea socialmente deseable expresarla.

Partiendo del presupuesto que las personas tendemos a ocultar las conductas, actitudes u opiniones que sabemos que están estigmatizadas o que suscitan desaprobación social, debimos definir la estrategia metodológica más adecuada para la investigación. De acuerdo con Cea D'Ancona y Valles (2010), la metodología de enfoque cualitativo favorecería el descubrimiento de lo que tiende a ocultarse debido a la indeseabilidad social, en la medida que sus técnicas de relevamiento de información, particularmente la 
entrevista en profundidad, buscan generar mediante su aplicación un marco de situación favorable a establecer empatía entre el entrevistador y el entrevistado, creando un ámbito propicio para que este último exprese sus ideas con plena confianza.

De este modo, es habitual encontrar estudios que parten de analizar representaciones sociales mediante aproximaciones basadas en enfoques de tipo cualitativo, sustentados por entrevistas en profundidad y grupos focales. Es el caso de nuestra labor en investigaciones en las que hemos participado en proyectos anteriores que se proponían conocer las representaciones sociales que se construyen y reproducen tanto en las escuelas del AMBA como en el poder judicial de la Nación, aportándonos una considerable experiencia analizando el modo en que se expresan las representaciones sociales de los nativos de dichas instituciones acerca de varios colectivos migrantes y proporcionándonos a la par una fuente importante de conocimiento previo acerca del objeto de estudio.

El haber ya transitado por esa experiencia, sumado a la inquietud de incursionar en la problemática a través de un enfoque cuantitativo, con la intención de aproximarnos a un universo mayor compuesto por jóvenes, y testear la adecuación de este enfoque a nuestros intereses, fueron algunas de las cuestiones que nos inclinaron a definirnos por la implementación de la encuesta, en tanto técnica de relevamiento de información a la que entendemos apropiada si se toman los recaudos necesarios para ajustarla a los requerimientos del logro de los objetivos planteados.

Entendemos que ésta se presenta como una técnica propia del quehacer científico que ofrece la posibilidad de recolectar información a través de la utilización de cuestionarios estandarizados, los cuales pueden ser administrados, ya sea por entrevistadores capacitados para tal fin, o distribuidos para su administración a una muestra. La encuesta suele utilizarse para obtener información sobre actitudes, creencias y opiniones de los individuos estudiados al indagar sobre diversos temas (Marradi et al., 2012), constituyéndose en un recurso metodológico adecuado para relevar muchas propiedades referidas a varios individuos.

No obstante estas ventajas, también tomamos en consideración las limitaciones que este enfoque podía llegar a presentarnos, como ser la alta tasa de no respuesta por parte de los encuestados, que pudiera ser ocasionada producto de la falta de comprensión de las consignas del cuestionario, la falta de interés en el estudio, etc. Lo habitual para reducir la tasa de no respuesta suele ser la implementación de estrategias de motivación y sensibilización de los encuestados, así como la previa notificación de la visita del encuestador. Aunque es preciso advertir que la implementación de dichas estrategias depende en parte de los recursos con que se cuenten y de la población seleccionada (Rodríguez Osuna, 1994)4. 
En cuanto a la implementación de las estrategias de motivación y/o sensibilización de la población en estudio a fin de reducir la tasa de no respuesta, debemos mencionar que una vez que conseguimos ingresar a las aulas de las escuelas, el control para reducir los casos de no respuesta se implementó explicando y concientizando a los estudiantes sobre la importancia que tenía para nuestro trabajo de investigación y para la calidad de los datos, el hecho de plasmar sus opiniones respondiendo con honestidad el cuestionario.

Asimismo, y debido a que las encuestas fueron realizadas intencionalmente en horario de clases, dentro del marco institucional y presentado en el aula por autoridades de la escuela, la misma fue anunciada como una actividad "obligatoria”, si bien se aclaró que tenían la posibilidad de retirarse del aula quienes no quisiesen responderla ${ }^{5}$. Esta coacción ejercida sobre los alumnos, si bien podría afectar negativamente el resultado de las encuestas, debido a la presión que pudiesen sentir por dar respuestas "políticamente correctas", tuvo como contrapartida una muy baja tasa de no respuestas (cercana al 0,5\%).

Cabe destacar que definimos a la estrategia implementada por el propio equipo de investigación como "encuesta autoadministrada dirigida" en un contexto de grupo. Esto significa que, si bien cada una de las personas encuestadas son quienes llevan a cabo la tarea de responder el cuestionario, los encuestadores están presen- tes para hacer aclaraciones, supervisar que los cuestionarios sean respondidos y controlar la dinámica de la situación de encuesta. El beneficio que obtuvimos mediante la estrategia adoptada, que combina la situación de autoadministración con la presencia de un encuestador, se resume en la posibilidad de aclarar dudas que pudieran surgir durante la aplicación del instrumento de registro y el control de que fuera respondido de manera individual; el hecho de no tener que restringir la extensión del cuestionario por alguna incomodidad que pudiera presentar la situación durante la aplicación del instrumento; el favorecer el acceso a un segmento poblacional que con ausencia de los encuestadores se vería reacio a responder ante la interpelación de las preguntas del cuestionario, como es el caso de jóvenes en edad escolar en escuelas cuya matrícula se compone por estudiantes nativos y migrantes, más aún, cuando la temática sobre la cual se los interpela refiere a las relaciones interculturales que se dan en la vida cotidiana en general y en la institución educativa en particular.

Nuestra estrategia también supuso la implementación del método de muestreo opinático, resultando en un total de 260 casos. El mismo es definido por Rodríguez Osuna (1994) como aquel cuyo abordaje de los sujetos viene dado según criterios del investigador y cuya selección se da en forma que la muestra sea lo más representativa a los efectos de la investigación que se pretende realizar. Partimos del supuesto que tanto el barrio seleccionado, como las escuelas a las 
que tuvimos acceso para llevar a cabo el trabajo de campo, según nuestra experiencia e indagación previa, asumen las características apropiadas para estudiar el problema objeto de nuestra investigación.

En este sentido, la presencia de los encuestadores resultó eficiente para llegar a un segmento poblacional de difícil acceso y, sobre todo, concentrado espacialmente.

En relación con el diseño del cuestionario, incorporamos diversas estrategias. En este sentido, la encuesta que aplicamos comienza con una batería de preguntas que apuntan a la "Asociación libre de palabras" (Di Giacomo 1981). Esta técnica nos parece apropiada dado que libera a los sujetos del control cognitivo impuesto por la deseabilidad social. También incorporamos preguntas abiertas en las que los estudiantes debían formular las respuestas por sí mismos y no verse restringidos a optar por alternativas cerradas predefinidas de antemano. En otros casos, y para hacerlo más didáctico, incluimos cuadros con varias alternativas de respuestas posibles, de forma tal que también minimizara la presión social en las respuestas.

Posteriormente, incluimos preguntas con ejemplos concretos, planteando situaciones posibles en las que pudieran verse involucrados en su experiencia áulica, donde debían responder por algunas de las opciones que les brindábamos. Asimismo, hacia el final del cuestionario fue- ron planteadas preguntas a partir de las cuales pudieran mencionar las posibles soluciones que ellos darían a los problemas identificados como una forma de involucrarlos en el proyecto. Finalmente, hemos utilizado diferentes escalogramas que permitieran estandarizar las distintas representaciones sociales acerca de las poblaciones migrantes.

Una parte de los hallazgos que arrojó la realización del estudio son presentados en este artículo. El mismo se centra en analizar las representaciones sobre uno de los grupos nacionales, a saber, la comunidad boliviana. Ello se debe al hecho de que, al decir de los estudiantes y evidenciado por nuestra investigación, es el grupo más discriminado en la escuela.

También es importante destacar que aquí hemos puesto el foco en analizar las respuestas a tres preguntas referidas a las representaciones sociales acerca de la comunidad boliviana que fueron formuladas como preguntas abiertas en el cuestionario, pero a la vez limitadas a ser respondidas por asociación libre con una sola palabra. Las mismas fueron analizadas mediante un proceso que conjugó la aplicación de la Teoría Fundamentada (Glaser y Strauss, 1967) 6 -utilizada en abordajes cualitativos-, la que nos permitió la agrupación de respuestas y la construcción de categorías, y el posterior procesamiento a través del programa SPSS.

El método de la Teoría Fundamentada implica 
inicialmente una codificación abierta para estimular el descubrimiento de categorías, propiedades y dimensiones de análisis. Posteriormente, la codificación axial consistió en un proceso guiado por la búsqueda de reducción de categorías, facilitando el entrelazamiento de codificación-grillado y el análisis de contenido de los discursos e interpretación de la información obtenida. En este caso, realizamos dos cierres a partir de las palabras ofrecidas como respuestas por los estudiantes. En el primero fueron establecidas numerosas categorías, y posteriormente ellas fueron agrupadas en categorías teóricas. Este proceso puede verse reflejado en el análisis que se presenta a continuación.

\section{Resultados}

A continuación, presentamos algunos de los resultados obtenidos tras el tabulado de la información y su agrupamiento en categorías teóricas. Los primeros tres gráficos refieren al primer bloque de preguntas del cuestionario. Se trata de preguntas abiertas referidas a diversos grupos de origen migrante, aunque aquí solo presentamos los resultados para la nacionalidad boliviana. Seguidamente, se presentan los datos volcados en gráficos que responden al último bloque de preguntas del cuestionario, referidos a la representación que los alumnos tienen sobre el grado de discriminación en la escuela, y el lugar dado a dichos temas en las clases. En estos dos últimos casos, se trató de preguntas realizadas con escalogramas, en los cuales los estudiantes debían asignar puntajes del 1 al 5.
Respecto al primer bloque, la primera pregunta solicitaba a los alumnos que respondieran: ¿Con qué palabra describirías a cada una de las personas de las siguientes nacionalidades?

Puede observarse que el mayor porcentaje de respuestas referidas al caso de la nacionalidad boliviana se concentra en la categoría "marcador de diferencia" $(25,7 \%)$. En ella, agrupamos aquellas palabras que referían a aspectos que señalan al otro como portador de características extrañas, distintas y distantes. Estas diferencias pueden remitir a rasgos fisonómicos, al lugar de origen o a la mención del genitivo. En este sentido, se hace necesario recordar que la construcción de la narrativa de la historia argentina y por lo tanto la construcción de la identidad nacional se forjó a partir de la eliminación e invisibilización de las diferencias. En la misma línea, Briones (2008) refiere a las "formaciones nacionales de alteridad" para entender las particularidades de los procesos de configuración de la nación con respecto a cómo se articula la diferencia y la jerarquía. Mientras que Segato (2007) señala que la esperanza en el mito civilizador de la migración convivió, en los momentos de conformación del Estado Nación, con el prejuicio y el "terror étnico", para referirse a la voluntad de poblamiento de un país blanco-europeo.

Más allá de los cambios tanto materiales como discursivos a los que asistimos en la actualidad, las representaciones sociales vinculadas a la di- 
Gráfico $\mathbf{N}^{\circ} 1$ : Representaciones sociales generales respecto de población de origen boliviano en jóvenes escolarizados en Educación Media en escuelas públicas de Villa Lugano. Años 2015-2018.

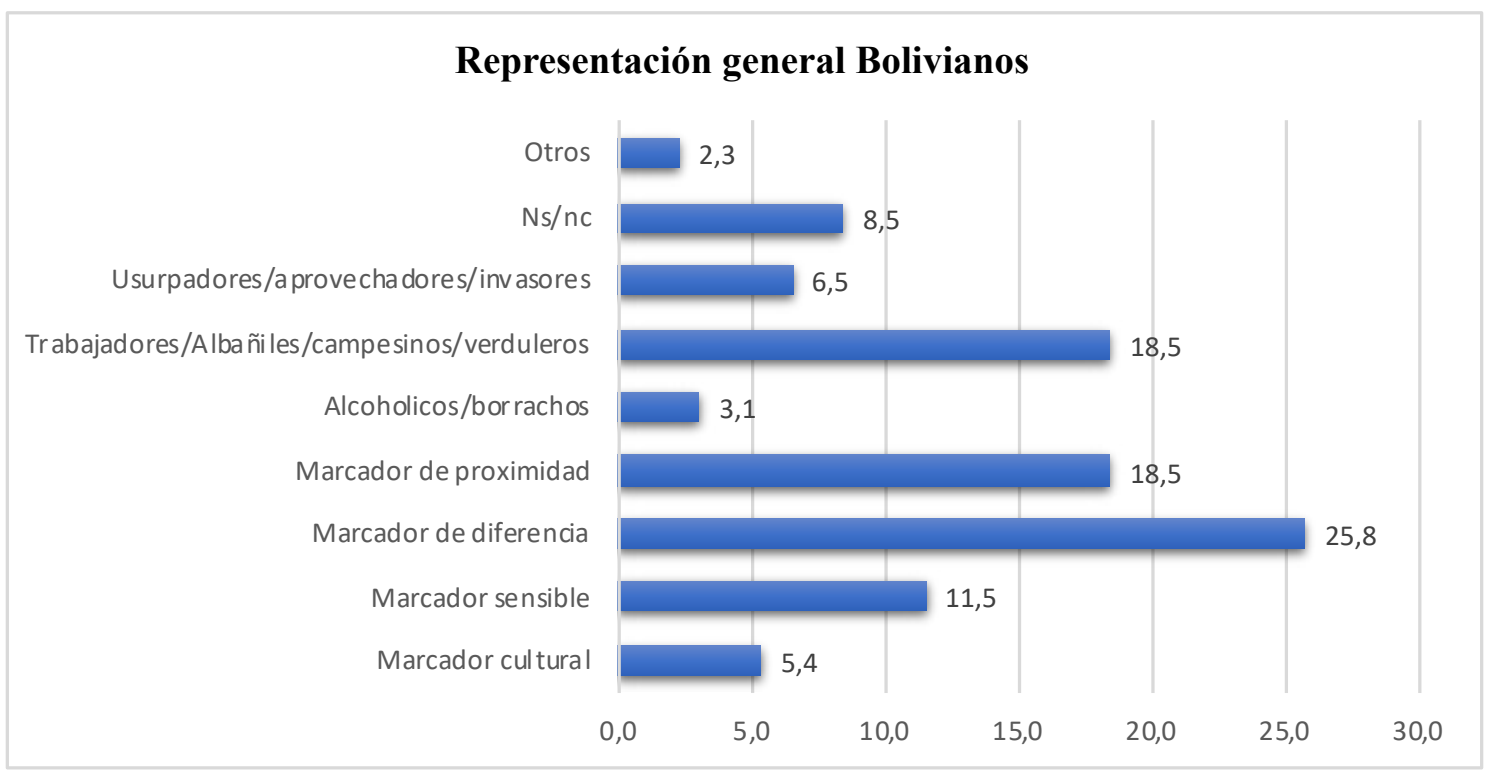

Fuente: Producción propia en base a datos construidos por el equipo de Investigación del Proyecto de Reconocimiento Institucional "Representaciones sociales de jóvenes y adultos hacia migrantes bolivianos, paraguayos, asiáticos y africanos en "barrios sur" de CABA. 2015-2018

ferencia, no negativas per se, adquieren un peculiar significando cuando son analizadas a la luz del caso argentino y del modo en que la diversidad fue constituyéndose como desigualdad. En ese sentido, aquellas respuestas que señalan a los bolivianos como "bolita", "boligoma" o "boliviano" fueron agrupadas aquí, poniendo en prominencia una delimitación en torno al eje nosotros-otros y estableciendo así un distanciamiento de un "otro" respecto del "ser con-nacional".

En cambio, la categoría a la que hemos dado en llamar "Marcador de proximidad" (18,5\%) agrupa aquellas respuestas que indican una representación de cercanía como contracara de la categoría anterior. Incluimos también respuestas que apuntan a la posibilidad de construir lazos con la población de dicho origen, o bien, que entienden que su integración (considerada en un sentido amplio) sería relativamente fácil por sus características, por ejemplo: términos tales como buenos, amigables, simpáticos, han sido incorporados aquí. También se ubican dentro de esta categoría representaciones tales como "amigos", "hermanos", "familia".

Por su parte, entendemos que cuando se señala a la población de origen boliviano como "trabajadores/albañiles/verduleros/campesinos" $(18,5 \%)$, los encuestados remiten a la asociación 
entre la bolivianidad y el trabajo, representados, por un lado, con la predisposición a ofrecer su fuerza de trabajo, pero también a la asignación de ciertos lugares o posiciones dentro de la estructura del mercado laboral circunscriptos a determinadas actividades de baja calificación y/o escaso prestigio social.

Cuando nos referimos a la categoría "Marcador sensible", aquella que con $11,5 \%$ se encuentra en cuarto lugar en cuanto a concentración de respuestas, lo hacemos para dar cuenta de una de las dimensiones -la sensible- que emergen al momento de expresar representaciones sociales acerca de un "otro". Para la construcción de esta categoría, nos basamos en los aportes de Olga Sabido Ramos (2012), quien nos ofrece una clave para poder interpretar el significado y la pertinencia del problema del extraño, en términos de enfocar un interés cognoscitivo en el cuerpo, y específicamente la percepción sensible. Tal perspectiva se orienta en ver en la aparición del "otro", emociones y estados afectivos tales como el miedo, la angustia o el asco, que surgen al no encajar con los esquemas "normales" de percepción. En este sentido, ese otro es aquel que es ajeno a los marcos de interpretación teóricos, estéticos, morales, religiosos, políticos, étnicos o lingüísticos del "nosotros". Remite así a formas de ser con otros, a formas que surgen de las interacciones en las que interactuamos con el cuerpo y significamos sensiblemente a los otros. El extraño deja de ser un estado para constituirse en un acontecimiento en el que intervienen perso- nas y pautas interpretativas que remiten no sólo a la mera conciencia de las personas sino a sus cuerpos y lógicas de percepción. Así, dentro de la categoría "Marcador sensible" encontramos representaciones que señalan a los bolivianos como "negros", "sucios" u "olorosos", todas representaciones que remiten a lógicas de sentir.

Además de tales modos en que agrupamos en categorías las representaciones que los sujetos producen acerca de la comunidad boliviana y se presentan como más destacados, existen otros que, si bien disminuyen en proporción, no dejan de tener importancia. Son los casos de las categorías definidas como "usurpadores/aprovechadores/invasores" que acumula al $6,5 \%$, aquella definida como "Marcador cultural" (5,4\%), y la categoría "alcohólicos/borrachos" en un 3,1\% de los casos relevados en la muestra.

La categoría de análisis "Usurpadores/aprovechadores/invasores" expresa la violación de fronteras, el no respeto a la norma y el avance sobre "nosotros", resultando como consecuencia de ello la ocupación de espacios que no son propios. Supone, asimismo, una connotación que alude a las acciones premeditadas. Compartimos con Cohen cuando afirma que tal modo de representar a la comunidad migrante denota la falta y demanda de control y sus consecuencias corrosivas. Dicho autor define "Una categoría común que une conceptualmente a la violencia, la violación de fronteras, la ilegalidad y las acciones premeditadas en la transgresión" (Co- 
hen, 2014:17). En este sentido, la transgresión adjudicada por parte de los jóvenes encuestados respecto de la comunidad boliviana estaría expresando que estos últimos invaden espacios que no les son propios, usurpando y aprovechándose premeditadamente, por ejemplo, de los servicios públicos tales como la salud, educación o planes sociales.

Finalmente, la categoría "Marcador cultural", menor en términos porcentuales de respuesta $(5,4 \%)$. En esta hemos agrupado aquellas respuestas que distinguen y resaltan las diferencias en términos de costumbres y que remiten a vestimentas típicas, comidas, bailes. Entendemos que estas respuestas agrupadas no tienen una connotación positiva ni negativa, sino que las consideramos de alguna forma neutra. En otro trabajo (González y Kleidermacher, 2018) nos hemos referido a ellas como "Representación iconográfica". En ambos casos hemos agrupado aquellas respuestas que dan cuenta de un imaginario común, a gustos y actividades compartidas por (o que se atribuyen a) un colectivo, donde se resalta una tradición e historia común. Por último, la categoría "alcohólicos/borrachos" expresa un modo de caracterizar a los bolivianos con hábitos condenables socialmente, adjudicando dicha etiqueta al colectivo migrante, que fueron mencionadas en $3,1 \%$ de los casos.

Entendiendo que por sí solas estas palabras no tenían necesariamente una connotación positiva o negativa, sino que apuntaban más bien a ex- presar representaciones generales acerca de las nacionalidades, solicitamos a continuación a los alumnos que respondieran a la siguiente consigna: "Elegí una palabra que describa lo que considerás mejor o lo que crees que es lo mejor de la forma de ser que tienen cada una de las siguientes nacionalidades". Presentamos los resultados para la nacionalidad boliviana.

Lo primero que nos ha llamado la atención al analizar el gráfico $\mathrm{N}^{\circ} 2$ es la alta concentración de respuestas en la categoría "Trabajadores", donde se encuentra el $31,5 \%$ de los casos. En dicha categoría hemos agrupado las respuestas que caracterizaban al colectivo como "verduleros", "cosecha" y "costura", principales ocupaciones que tienen en el mercado laboral argentino, así como también la palabra "trabajadores" que puede entenderse en dos sentidos: el hecho que trabajan y contribuyen a la economía del país, pero también las largas jornadas laborales por salarios escasos, hecho que ha sido mencionado en numerosas oportunidades, tanto en los medios masivos de comunicación como en discursos políticos, donde se hace alusión a la explotación que sufre el colectivo migrante de dicho origen.

En segundo lugar, se halla el "marcador de proximidad" con un $21,2 \%$ de respuestas. En esta categoría, tal como fue explicitado anteriormente, se concentran aquellas respuestas que representan al colectivo con características positivas y la posibilidad de establecer relaciones amistosas. 
Gráfico $\mathbf{N}^{\circ} 2$ : Representaciones sociales positivas respecto de población de origen boliviano en jóvenes escolarizados en Educación Media en escuelas públicas de Villa Lugano. Años 2015-2018

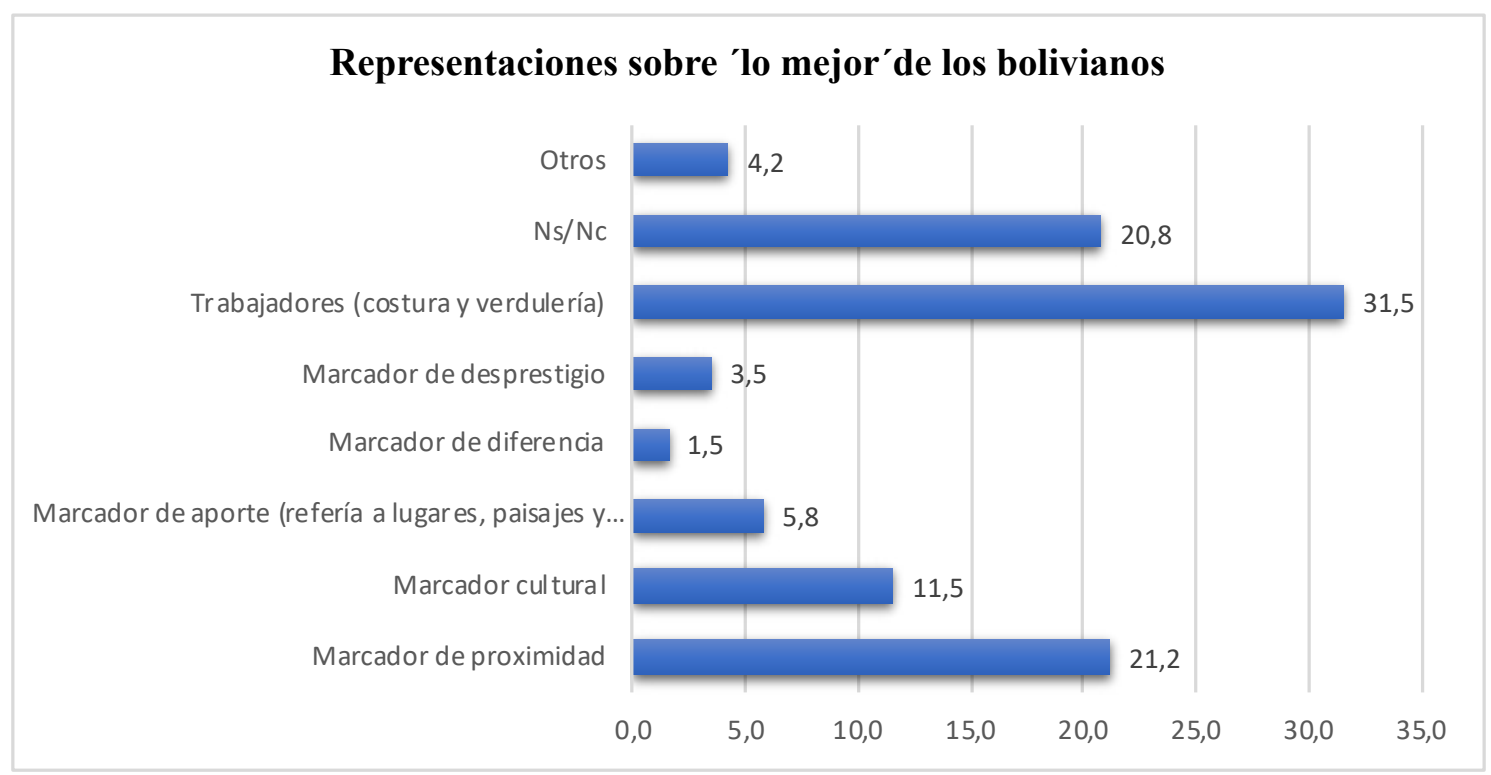

Fuente: Elaboración propia en base a proyecto anteriormente citado

Seguidamente, se halla con un alto porcentaje la categoría Ns/Nc $(20,8 \%)$, lo cual indica que una gran cantidad de estudiantes no han asignado un atributo positivo al colectivo de nacionalidad boliviana, hecho que no sucedió al solicitar una representación general (ver Gráfico $\mathrm{N}^{\circ} 1$ ).

Finalmente, y con un porcentaje muy menor de respuestas (11,5\%), se encuentra el "Marcador Cultural", descripto en el apartado anterior al analizar las representaciones generales.

Restan categorías con porcentajes comparativamente menores de respuestas, como "Marcador de aporte” $(5,8 \%)$, donde agrupamos respues- tas que hacían referencia a la minería del país y principalmente a sus paisajes, y el "Marcador de desprestigio" $(3,5 \%)$ que remite, tal como veremos al analizar el Gráfico $\mathrm{N}^{\circ} 3$, a características negativas, aun cuando se solicitaba referirse a aspectos positivos del colectivo.

Finalmente, en la tercera pregunta de este bloque solicitábamos a los alumnos de las escuelas de Villa Lugano, "Elegí una palabra que describa lo que consideras peor o lo que crees que es lo peor de la forma de ser que tienen cada una de las siguientes nacionalidades". Tras agrupar las respuestas, construimos las categorías que presentamos a continuación. 
Gráfico $\mathbf{N}^{\circ}$ 3: Representaciones sociales negativas respecto de población de origen boliviano en jóvenes escolarizados en Educación Media en escuelas públicas de Villa Lugano. Años 2015-2018

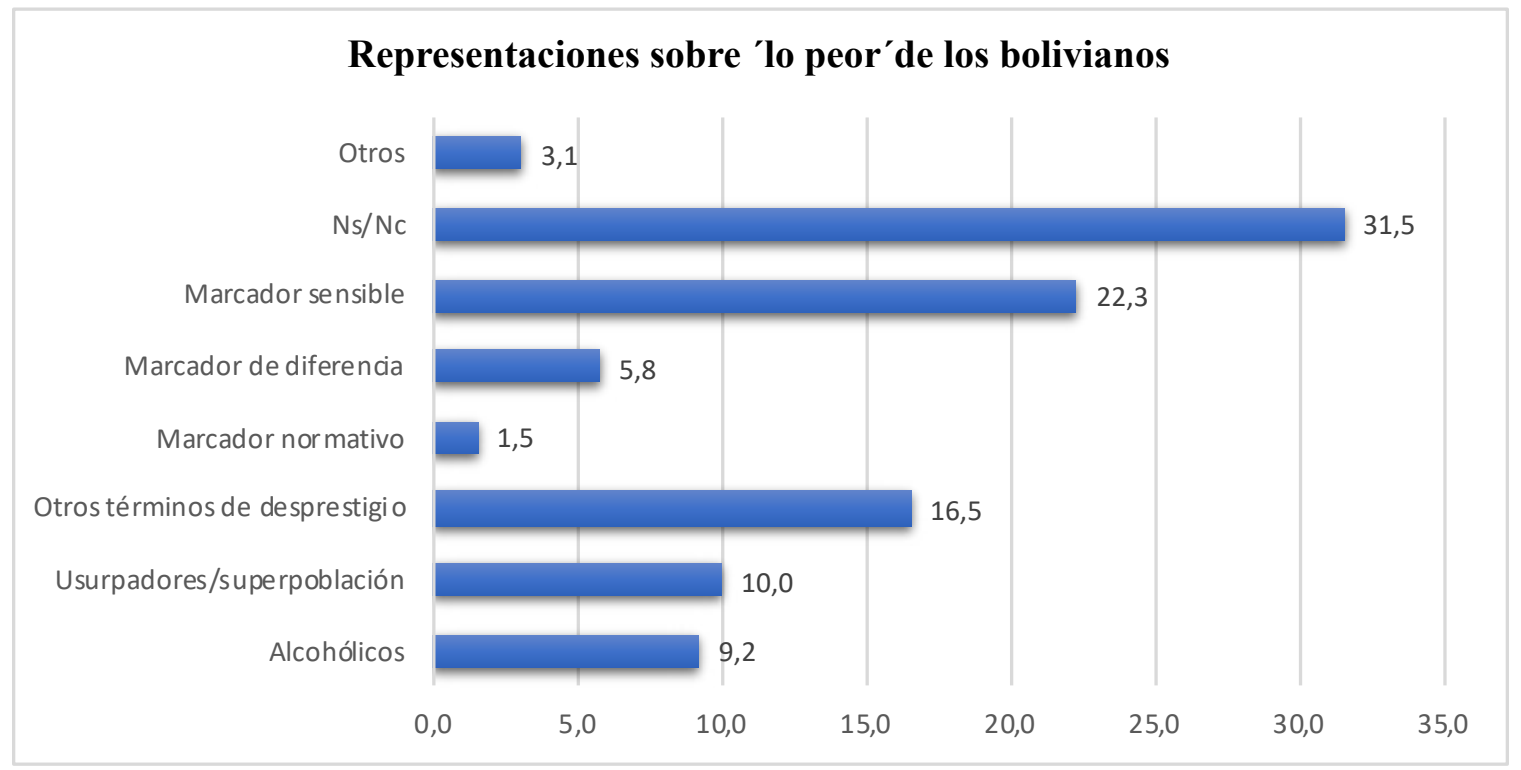

Fuente: Elaboración propia en base a proyecto anteriormente citado

La categoría que agrupa el mayor porcentaje de respuestas $(31,5 \%)$ es la de Ns/Nc. Interpretamos que la omisión a dar una respuesta puede darse por varios motivos, aunque aquí nos encontramos en un plano hipotético. Podrían darse casos en que los estudiantes se enfrentaran a la toma de conciencia frente al desconocimiento y por ende a sentirse compelidos a no asignar ningún atributo, ni negativo ni positivo acerca de la nacionalidad boliviana. Otra alternativa sería que realmente no encuentran motivos para la asignación de atributos, favorables o no, que vinieran dados a partir del origen etno-nacional. La tercera conjetura que podemos plantear es aquella mediante la cual la omisión a responder viniera condicionada a partir del sesgo de deseabilidad social, siendo el que motiva a no expresar aquello que se considera implica una condena social. Así pues, creemos necesario seguir indagando a futuro cuáles pueden ser los aspectos que, mediante los recursos metodológicos implementados en este estudio nos vemos limitados en responder.

En segundo lugar, se encuentra la categoría "Marcador Sensible" $(22,3 \%)$ que, tal como fuera analizado en el Gráfico $\mathrm{N}^{\circ} 1$, agrupa aquellas respuestas que refieren al olor y la suciedad, representaciones negativas del colectivo bolivia- 
no que pueden afectar las relaciones con ellos. Luego, con un $16,5 \%$ se halla el "Otros términos de desprestigio”, categoría en la cual agrupamos las respuestas que aludían a aspectos negativos con que los estudiantes de las escuelas de Villa Lugano eligieron para describir a la población de origen boliviano, como ser "ridículos", "mentirosos", "chantas" y "vagos". Hemos elegido este nombre ya que hay otras categorías que refieren a marcadores de desprestigio, pero cuyo peso porcentual hacía relevante mencionarlas por separado, como lo son "usurpadores" (10\%) y "alcohólicos" $(9,2 \%)$.

El primero de los términos agrupa respuestas que refieren a la superpoblación o gran cantidad de migrantes de origen bolivianos que estarían presentes en la Argentina, así como la usurpación de servicios sociales y de terrenos (entendemos que ello responde a la imagen de las Villas Miseria que concentran a personas de bajos recursos, muchos de ellos migrantes tanto internos como limítrofes). Mientras que el segundo término refiere, como ya hemos mencionado, a un hábito condenable en la sociedad argentina.

Por otra parte, consideramos enriquecedor ofrecer en este artículo otros datos construidos a partir de la información relevada. En la encuesta, consultamos a los alumnos cuál creían que era el grado de discriminación hacia los migrantes en la escuela, mediante la aplicación de un escalograma donde 0 significaba "nada" y 5 "mucho". En ese sentido, solo el 7,3\% de los alumnos res- pondió que no había discriminación, mientras que el $28,8 \%$ respondió que había un grado medio de discriminación hacia los alumnos de un origen nacional distinto al argentino.

Si bien el vocablo "discriminación" puede tener diversas acepciones, en este caso retomamos a la antropóloga argentina Corina Courtis (2010), quien observa que en el lenguaje diario, la noción de discriminación alude principalmente a prácticas de estereotipación discursiva y al trato diferencial percibido en numerosas instancias de interacción social, ya sea en espacios públicos o privados. Asimismo, y desde su trabajo en Francia, agrega Essed (1991) que la discriminación étnico racial incluye todos aquellos actos-verbales $\mathrm{y}$ no verbales- que tienen consecuencias negativas o desfavorables para colectivos dominados en virtud de una marcación racial o étnica.

Sería conveniente, con el fin de extender la comprensión de este complejo fenómeno, indagar qué entienden los encuestados por discriminación al señalar que la misma existe -o no- en la escuela. Suele suceder que los comportamientos y modos de vinculación grupal discriminatorios tienden a naturalizarse y formar parte del repertorio natural de acciones cotidianas; por lo tanto, las representaciones sociales en torno a si existe discriminación suelen variar con respecto a la existencia concreta de hechos discriminatorios que se producen en un grupo. Dan cuenta de esta brecha las características que los encuestados asignan a los distintos colectivos migrantes, 
Gráfico $\mathbf{N}^{\circ} 4$ : Representación social acerca del grado de discriminación hacia migrantes en las escuelas en jóvenes escolarizados en Educación Media en escuelas públicas de Villa Lugano. Años 2015-2018

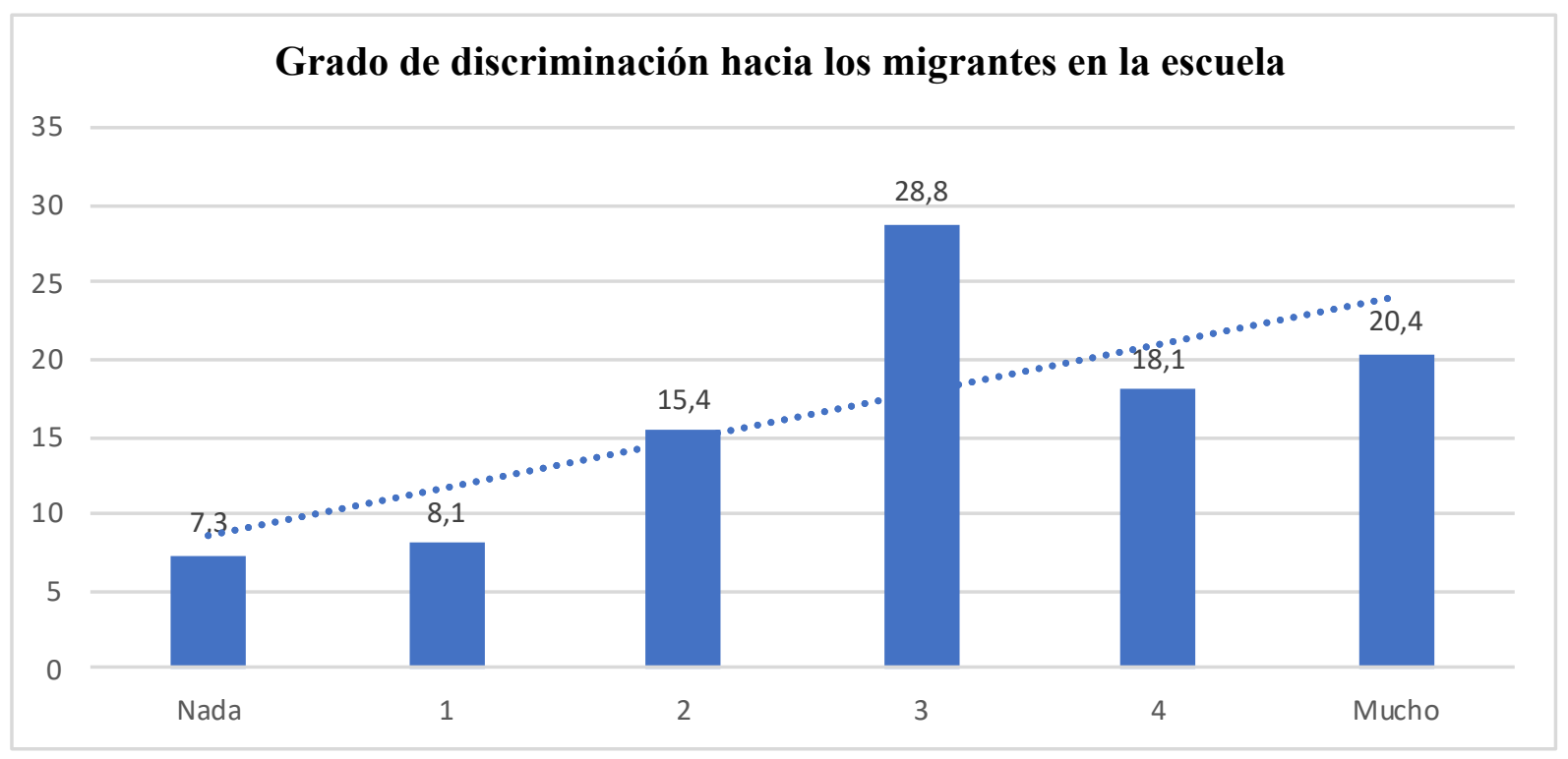

Gráfico $\mathbf{N}^{\circ}$ 5: Representaciones sociales respecto al lugar dado en la escuela a las temáticas migratorias según jóvenes escolarizados en Educación Media en escuelas públicas de Villa Lugano. Años 2015-2018

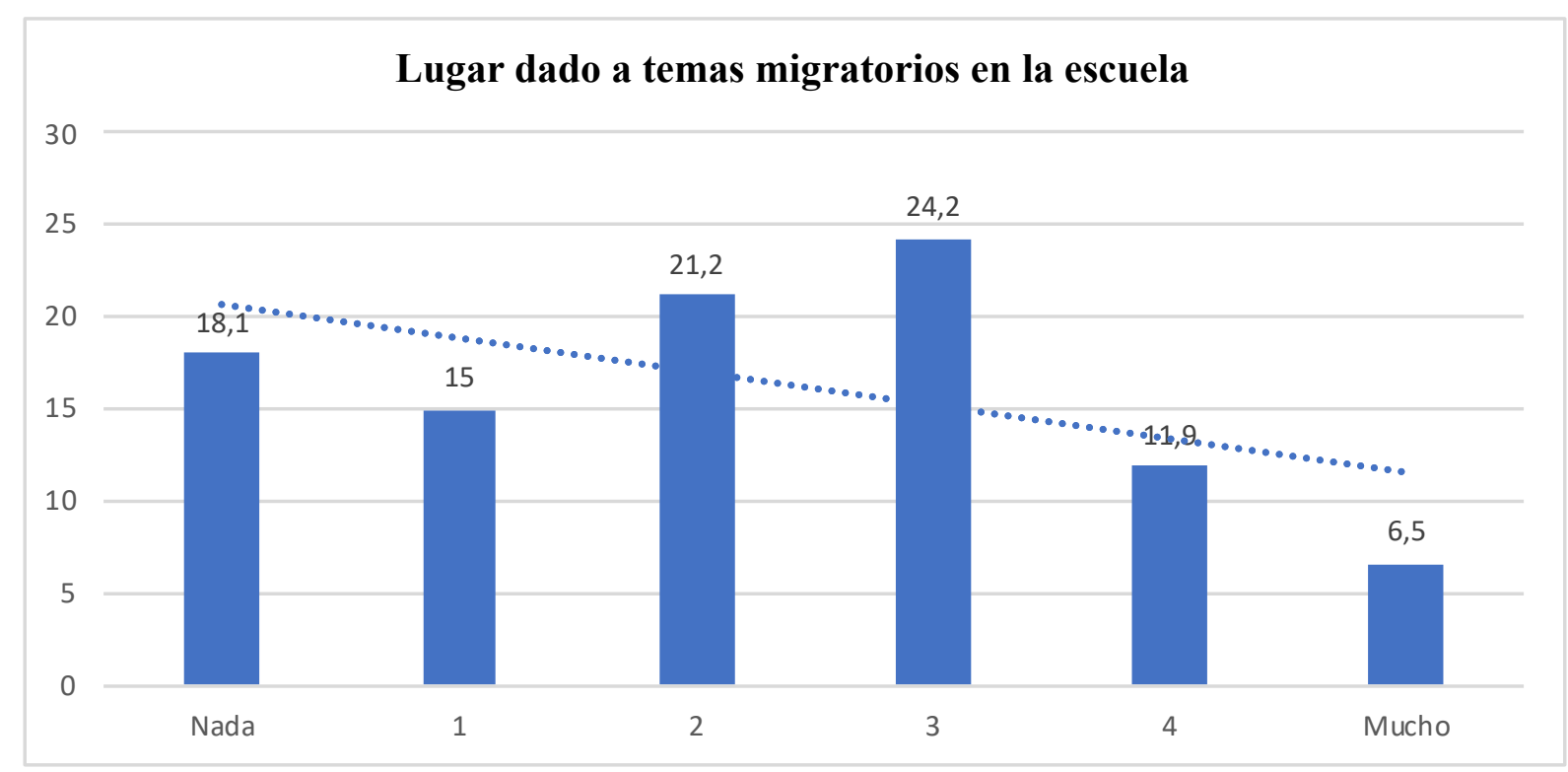

Fuente: elaboración propia en base a proyecto anteriormente citado 
extensamente descriptas dentro de los hallazgos del presente estudio.

Otra de las preguntas introducidas en el cuestionario era: "En una escala donde 5 es Mucho y 0 Nada, ¿Cuál crees que fue el lugar dado a los temas migratorios en la escuela (en libros de texto, en actividades en la clase y/o actividades especiales)?"

Entre las respuestas encontramos que el 18,1\% de los alumnos respondió "Nada" y un 15\% respondió "Muy poco", mientras que solo el 6,5\% de los alumnos ha respondido "mucho". Entendemos que se trata de un tema por demás relevante para contribuir al establecimiento de mejores relaciones interculturales en la escuela. Más aún si conceptualizamos que la institución escolar cumple un rol central en la administración de la diversidad étnica y cultural, en tanto constituye un agente de socialización. Si desde la escuela no se promueve una mirada "oficial" acerca del "otro", se vuelve más posible que en ella emerja un escenario plagado de representaciones e imágenes estereotípicas que en absoluto tienen que ver con las características del migrante "real".

En este sentido, los resultados de la propia investigación pueden alertar sobre la necesidad de incorporar a los temas migratorios en las curriculas y planes que se dictan. Incluso, desde la propia voz de los alumnos encuestados, puesto a que el $64 \%$ estaba de acuerdo en tener más actividades sobre la temática, frente a un $32 \%$ que no lo consideraba necesario.

Estos porcentajes pueden ser interpretados como expresión de una demanda de los propios estudiantes, ya no sólo como reflejo de un vacío de contenidos pedagógicos que les resultaría de interés, sino como un reclamo hacia la institución escolar para que intervenga desde la currícula sobre una problemática que los/as interpela en sus vínculos cotidianos al interior de las aulas.

Con relación al Gráfico $\mathrm{N}^{\circ} 6$, nos basamos para su elaboración en la pregunta del cuestionario ¿Crees que la escuela (profesores, preceptores, directivos) puede contribuir a que no haya discriminación? Tal como puede observarse, más de la mitad del total de alumnos encuestados, el $55 \%$, respondió afirmativamente, mientras que el $41 \%$ respondió de manera negativa.

Consideramos que la escuela tiene un rol central, no solo, como mencionamos anteriormente, en tanto institución a través de la cual el Estado administra la diversidad, sino también como institución en donde se producen y reproducen prejuicios y estereotipos en torno a las "otredades migrantes". En este sentido, la incorporación del tratamiento de temáticas como la migración y la discriminación desde una perspectiva intercultural, es una herramienta de central importancia y los alumnos parecen advertir este hecho.

No podemos extendernos en este aspecto parti- 
Gráfico $\mathrm{N}^{\circ}$ 6: Representaciones sociales de los jóvenes escolarizados en Educación Media en escuelas públicas de Villa Lugano respecto a la contribución de la escuela en la lucha contra la discriminación

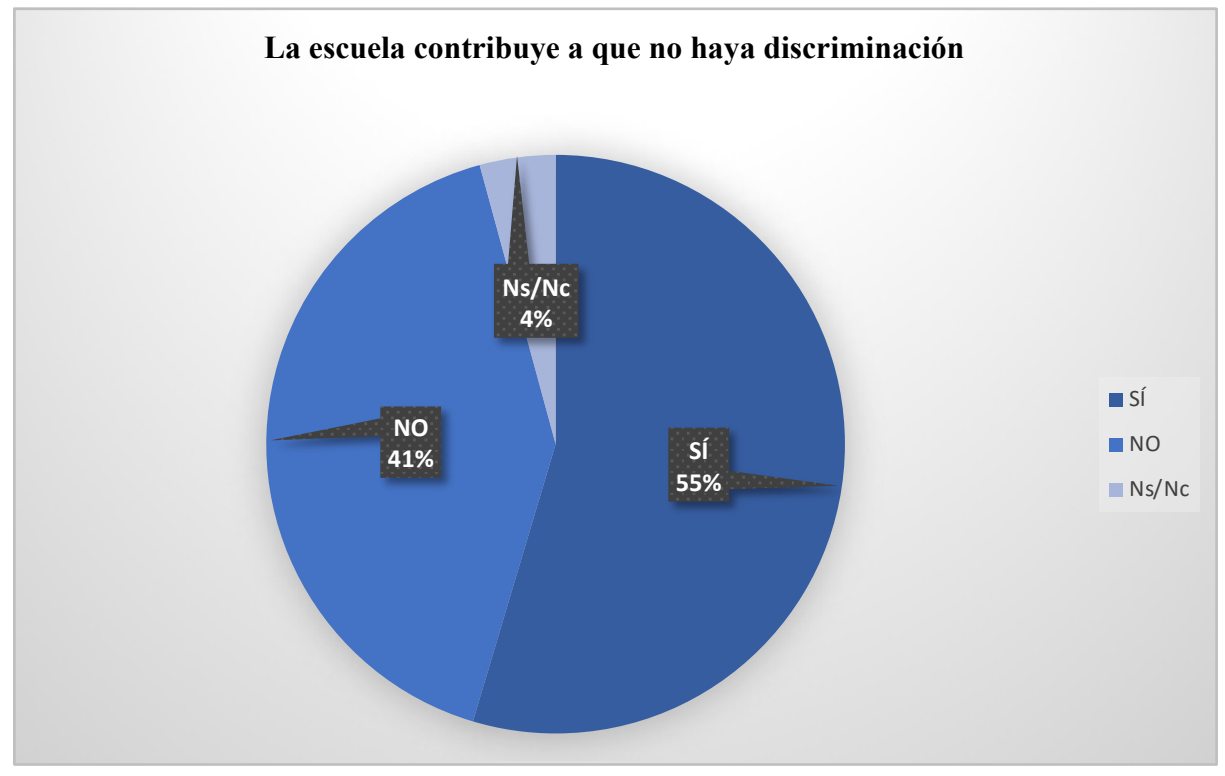

Fuente: Elaboración propia en base a proyecto anteriormente citado

cular que merecería un trabajo aparte, pero no queremos dejar de mencionar la importancia de la implementación de la educación intercultural como una de las formas de romper con la historia hegemónica de una cultura dominante y otras subordinadas y, de esa manera, reforzar las identidades tradicionalmente excluidas para construir, en la vida cotidiana, una convivencia de respeto y de legitimidad entre todos los grupos de la sociedad (Walsh, 2005: 4).

Siguiendo a la autora, "el sistema educativo es uno de los contextos más importantes para desarrollar y promover la interculturalidad, ya que es la base de la formación humana y un instru- mento no sólo de mantenimiento de una sociedad, sino de desarrollo, crecimiento, transformación y liberación de esa sociedad y de todas sus potencialidades humanas" (Walsh, 2005: 11). Tomando en consideración esta perspectiva de la educación intercultural, se torna aún más relevante el reconocimiento de la diversidad, pero también su tratamiento para que no se torne en desigualdad (Cohen, 2009).

Por último, les consultamos a los estudiantes si les gustaría recibir algún tipo de actividad donde se analicen esos temas (migraciones y discriminación). Como se desprende del Gráfico $\mathrm{N}^{\circ} 7$, el $64 \%$ de los alumnos encuestados respondió 
Gráfico $\mathbf{N}^{\circ} 7$ : Representaciones sociales de los jóvenes escolarizados en Educación Media en escuelas públicas de Villa Lugano respecto al deseo de trabajar con propuestas de actividades referidas a la temática migratoria.

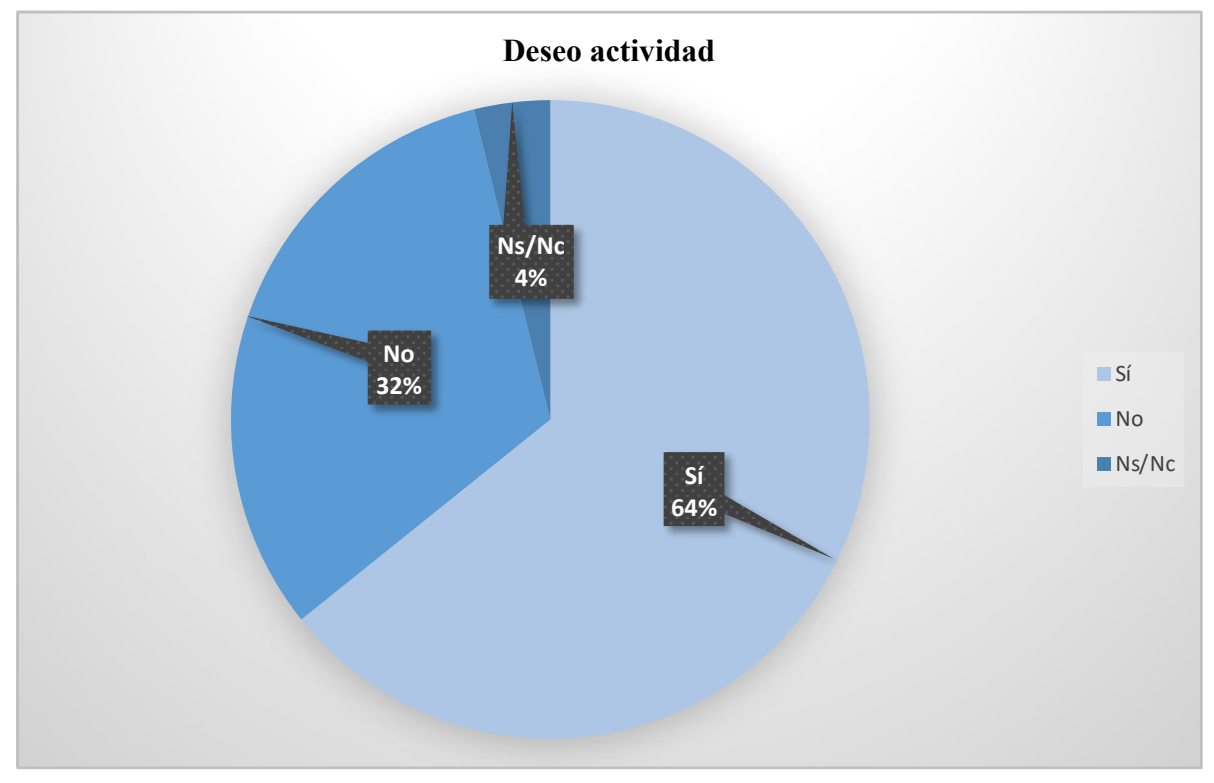

Fuente: Elaboración propia en base a proyecto anteriormente citado

afirmativamente, mientras que sólo el 32\% respondió de manera negativa.

Entendemos junto a Walsh (2005) que para tener un verdadero impacto en los alumnos y en la sociedad, la interculturalidad tiene que partir de la experiencia de los alumnos y de la realidad sociocultural en que viven, incluyendo los conflictos internos, inter e intragrupales, los desequilibrios sociales y culturales que ellos confrontan.

Para ello desarrollamos una actividad con los alumnos de una de las escuelas donde aplicamos la encuesta. En la misma presentamos los resul- tados que arrojó el estudio a la luz de diversas actividades donde discutimos los conflictos en el aula y fuera de ella y la discriminación y racismo que pesa sobre los migrantes de origen boliviano, paraguayo y peruano, principalmente.

De esta forma, nos propusimos echar luz sobre los vínculos que se constituyen en las aulas a partir de hacer emerger las representaciones que los jóvenes manifiestan y darles voz, además, para expresar en qué medida la escuela se hace eco de ello, desde sus prácticas y el lugar dado a su tratamiento. 


\section{Conclusión}

Entendemos que la forma en que se representa a las personas de origen boliviano en los jóvenes encuestados de las escuelas de Villa Lugano expresa representaciones sociales discriminatorias, donde se marca una diferencia en términos de establecer una distancia entre "nosotros" y "ellos", y esa diferencia es además puesta en una escala jerárquica a través de una mirada inferiorizante donde "los otros" son portadores de características negativas que dificultan el establecimiento de relaciones entre pares, es decir, que se presentan como inhabilitados para construir vínculos simétricos con "ese otro". Ello pudo verse claramente en el Gráfico $\mathrm{N}^{\circ} 1$, donde la mayor concentración de respuestas se observa en la categoría "Marcador de Diferencia", con casi un $26 \%$.

En el caso de la segunda pregunta, donde se solicitaban palabras para describir aspectos positivos, la mayor parte de las respuestas (31\%) se concentró en la categoría "Trabajadores", que, tal como fue analizado en el Gráfico $\mathrm{N}^{\circ} 2$, agrupa palabras como "verduleros", "costureros" y "trabajadores". Si bien puede entenderse como un aspecto positivo, entendemos que también esta categoría marca una distancia entre "nosotros" y "ellos", donde el último grupo sería visto únicamente desde una posición social ligada a trabajos no calificados y que no tienen prestigio en la sociedad.

Finalmente, si tomamos la categoría que más frecuencias porcentuales concentra en la tercera pregunta, donde les solicitamos a los alumnos que respondieran por los aspectos que consideraban negativos, encontramos que el $22,3 \%$ de los alumnos han mencionado palabras que agrupamos en la categoría "Marcador sensible", la cual refiere, siguiendo a Olga Sabido (2012), a aspectos sensoriales que generan sensaciones corporales, en este caso, de distanciamiento, asco o rechazo, debido al olor y suciedad con las cuales han representado al colectivo.

A modo de síntesis, podemos ver que la primera pregunta apuntaba a que los estudiantes expresaran una representación general acerca del colectivo migrante, mientras que la segunda y la tercera pregunta ofrecían la posibilidad de manifestar representaciones positivas y negativas, respectivamente. Así pues, establecer diferencias a fin de generar distancia, asignar lugares de bajo prestigio en la sociedad y manifestar rechazo desde una lógica de percepción sensible acerca del "otro", son tres de los principales modos, separados desde el análisis pero articulados en modos de representar, que tienen los estudiantes de las escuelas de Villa Lugano que están presentes como miradas anticipatorias de las relaciones que mantienen en sus ámbitos de socialización y que obtuvimos como parte de los resultados de nuestra investigación.

Novaro (2011) sostiene que "nombrar al otro no solo es una forma de reconocerlo, sino que también puede ser una forma de marcación en 
tanto que un término lleva asociado un significado peyorativo que se impone sobre alguien" (Beheran, 2012: 210). Este hecho es de gran significación, ya que entendemos que las palabras que los alumnos han respondido, y que mediante un trabajo de codificación hemos agrupado en categorías teóricas, tienen un contenido discriminatorio. Más aún, los propios alumnos, al ser consultados respecto a la existencia de discriminación en las aulas, han respondido afirmativamente. Si bien en las preguntas que aquí presentamos no se hacía referencia a alumnos de estas nacionalidades sino a la nacionalidad en general, consideramos junto a Essed (1991) que la discriminación incluye todos aquellos actos -verbales y no verbales- que tienen consecuencias negativas o desfavorables para colectivos dominados, en este caso, el boliviano. Es decir, que la representación negativa respecto a la nacionalidad boliviana tiene consecuencias concretas en las relaciones que se entablan con los alumnos de dicha nacionalidad en las aulas.

Tal como entendemos a las representaciones sociales, en tanto mirada hacia la alteridad, consideramos que el núcleo representacional tiene implicancias en el núcleo de la acción, en predisposiciones para la acción, generando relaciones interculturales portadoras de tensiones y productoras de asimetrías, al interior de las cuales la diversidad étnica se constituye como desigualdad (Cohen, 2009), en donde la discriminación racial y la xenofobia no son más que justificantes a este trato desigual. Finalmente resaltamos que el racismo como diferenciación biológica no existe, pero adherimos a la teoría del racismo cultural como otra forma de establecer jerarquías al interior de la población, siendo la institución educativa uno de los ámbitos donde las diferencias se manifiestan.

En segundo lugar, consideramos que el rol de la escuela se vuelve esencial no sólo como segundo espacio de socialización- luego de la familia-, sino como espacio de integración social y educativa.

A modo ilustrativo, vale retomar que en cuanto a la pregunta planteada a los estudiantes respecto de cuál creían que era el grado de discriminación hacia los inmigrantes en la escuela, pudimos observar una línea de tendencia ascendente entre las alternativas extremas "Nada" (7,3\%) / "Mucho" (20,4), aunque concentrándose en los puntajes de valores medios. Es decir que con sus respuestas afirmaban en mayor proporción que el grado de discriminación en la escuela tiende a ser alto. Por otro lado, evidenciamos una línea de tendencia descendente que grafica que el lugar dado a los temas migratorios en el ámbito de la institución es bajo. El 18,1\% dijo que no se le da nada de lugar, frente al 6,5\% que respondió que el espacio dado a estos temas es alto. La lectura que se puede concluir de ello es que la escuela contribuye tanto si ejecuta activamente políticas para gestionar la diversidad, como si omite con su participación curricular el tratar la problemática intercultural al interior de sus espacios. Los resultados son elocuentes como para 
sugerir que es deseable y necesario implementar acciones para revertir estas tendencias.

A pesar de ello, ante la pregunta referida a si consideraban que la escuela contribuye en la lucha contra la discriminación, más de la mitad de los alumnos (55\%) respondió de manera afirmativa. Aunque también es muy alto el porcentaje de aquellos que consideran lo contrario (41\%). Podríamos preguntarnos si esta representación de los que creen que la escuela sí contribuye en la lucha contra la discriminación no se sustenta en una percepción acerca del deber ser de la institución en términos de expectativas depositadas en ella para gestionar el conflicto o problemáticas presentes en la sociedad en general que permean los muros de las escuelas, y en donde ésta debería colaborar en dar solución, a fin de promover tanto la integración social como educativa.

Un análisis más profundo de la cuestión acerca de cómo y cuáles son las estrategias que se implementan en la escuela para abordar tal problemática merecen un tratamiento aparte, dado que aquí no fueron planteadas como parte de nuestros objetivos de investigación, aunque sí constituyen algunos de los interrogantes de nuestro próximo proyecto.

De todas formas, el conocimiento previo producto de la experiencia de investigación en esta temática nos permite sostener que la escuela tiende a naturalizar y promover determinados criterios morales de verdad y de deber ser. En este sentido, por un lado, en ella se reproduce un modelo culturalmente homogéneo a partir del cual se implementan estrategias de control y disciplinamiento social y se instauran modos de relación social de dominación respecto a las poblaciones migrante y nativa (Cohen, 2009).

En función del marco teórico que sustenta el presente proyecto, es posible afirmar que el código moral hegemónico al que se hace referencia, y que se produce y reproduce en la escuela, atraviesa los discursos de los jóvenes -encuestados en calidad de alumnos de la institución educativa- y colabora en la producción de sus representaciones sociales acerca de determinados colectivos de migrantes y de las relaciones interculturales. Si bien no ha sido objeto del presente escrito, cabe mencionar que también el contexto social en el cual son producidas las representaciones es relevante en este caso, y tal como fue mencionado al comienzo, se trata de un barrio de bajos recursos económicos y con alta presencia de población de origen migrante.

Retomamos finalmente el concepto de inclusión educativa planteado por Booth y Ainscow (2002), quienes la conciben como un proceso vinculado con su opuesto -la exclusión-, y en el cual la participación ocupa un lugar central: a inclusión en educación implica procesos para aumentar la participación de los estudiantes y para reducir su exclusión, en la cultura, la currícula y las comunidades de las escuelas. Implica reestructurar la cultura, las políticas y las prácticas de 
los centros educativos para que puedan atender la diversidad del alumnado de su localidad; se refiere al aprendizaje y la participación de todos los estudiantes vulnerables de ser sujetos de exclusión, al desarrollo de las escuelas tanto del personal como del alumnado y al refuerzo mutuo de las relaciones entre los centros escolares y sus comunidades. En ese sentido, planteamos una última pregunta en el cuestionario, donde consultamos a los alumnos respecto a la voluntad de tener actividades sobre estas temáticas: un $64 \%$ de ellos respondió afirmativamente, y es por este motivo que, tras finalizar el análisis de la investigación, regresamos a una de las escuelas del barrio para desarrollar una actividad que concientice respecto a los estereotipos, la discriminación y las vivencias de los jóvenes migrantes. La misma contó con un alto grado de participación y el compromiso de la escuela y el nuestro de seguir desarrollando actividades en esa línea.

\section{Refrencias citadas:}

Abric, J. (1994): Prácticas sociales y representaciones, México D. F., Ediciones Coyoacán.

Beherán, M. (2012): “Migraciones y educación en la Argentina. Transformaciones y continuidades, en S. Novick, Comp., Migración y políticas públicas. Nuevos escenarios y desafíos, Buenos Aires, Catálogos, pp. 201-225.

Benhabib, S. (2005): Los derechos de los otros. Extran- jeros, residentes y ciudadanos, Barcelona, Editorial Gedisa.

Booth, R. y M. Ainscow (2002): Indice de inclusión. Desarrollando el aprendizaje y la participación en las escuelas, Bristol, CSIE-UNESCO.

Briones, C. (2008): "Diversidad cultural e interculturalidad: ¿De qué estamos hablando?”, en C. García, Comp., Hegemonía e interculturalidad: Poblaciones originarias y migrantes. La interculturalidad como uno de los desafíos del siglo XXI, Buenos Aires, Prometeo, pp. 35-58

Caggiano, S. (2008): “Racismo, Fundamentalismo Cultural y Restricción de Ciudadanía: formas de regulación social frente a inmigrantes en Argentina", en S. Novick, Comp., Las migraciones en América Latina. Políticas, culturas y estrategias, Buenos Aires: Catálogos-CLACSO, pp. 31-51.

Cea D`Ancona, M. y M. Valles Martinez (2010): Xenofobias y xenofilias en clave biográfica, Madrid, Siglo XXI Editores.

Cohen, N. (2009): “Una interpretación de la desigualdad desde la diversidad étnica”, en N. Cohen, Ed., Representaciones de la diversidad: trabajo, escuela $y$ juventud, Buenos Aires, Ed. Cooperativas, pp. 11-29.

Cohen, N. (2014): “Dominación y migraciones externas”, Onteaiken. Boletín sobre prácticas y estudios de acción colectiva, 17(9), Córdoba. 
Courtis, C. (2010): Discriminación étnico-racial. Discursos públicos y experiencias cotidianas. Un estudio centrado en la colectividad coreana, Buenos Aires, Del puerto.

Di Giacomo, J. P. (1981): “Aspects méthodologiques de L'análise des représentations sociales”, Cahiers de Psychologie Cognitive, 1, pp. 397-422.

Essed, P. (2010): "Hacia una conceptualización del racismo como proceso", en O. Hoffman y O. Quintero, Estudiar el racismo. Textos y herramientas. Documentos de trabajo $\mathrm{N}^{\circ} 8$, México, Proyecto AFRODESC/EURESCL.

Ferrão Candau, V. M. (2010): “Educacion intercultural en América Latina: distintas concepciones y tensiones actuales", Estudios pedagógicos, 36(2), pp. 333-342

García Canclini, N. (2004): Diferentes, Desiguales y Desconectados. Mapas de la Interculturalidad, Barcelona, Gedisa Editorial.

Glaser, B. y A. Strauss (1967): The discovery of Grounded Theory: strategies for qualitative research, New Brunswick, Aldine.

Gonza, I. y D. Lanzetta (2011): “Sumisos, lentos y feos: representaciones sociales en torno a migrantes bolivianos en la institución educativa. El 'crisol de razas' hecho trizas", en VI Jornadas de Jóvenes Investigadores. Instituto de Investigaciones Gino Germani, Buenos Aires, Facultad de Ciencias Sociales,
Universidad de Buenos Aires.

González, A. y G. Kleidermacher (2018): “Representaciones sociales de la 'identidad argentina' en la población nativa residente en la Ciudad Autónoma de Buenos Aires”, Revista Civilizar Ciencias Sociales y Humanas, 18(34), pp. 135-148.

INDEC (2012): Censo Nacional de Población, Hogares y Viviendas 2010, Buenos Aires, Instituto Nacional de Estadísticas y Viviendas 2010. Disponible en web: http://www.censo2010.indec.gov.ar/cuadrosDefinitivos/analisis_censo_feb12.pdf

Jodelet, D. (1986): “La representación social: fenómenos, conceptos y teoría”, En S. Moscovici, Psicología Social, Barcelona, Paidós, pp. 469-494.

Kleidermacher, G. y D. Lanzetta (2018): “Miradas en la escuela. Representaciones de adolescentes respecto a migrantes bolivianos, paraguayos, asiáticos y africanos en Buenos Aires”, en R. Baeninger et al., org., Migrações sul-sul, Campinas, Núcleo de Estudos de População (NEPO) - UNICAMP, pp. 120-130.

Malegarie, J. y D. Lanzetta (2012): "La escuela hoy: una visión sobre los alumnos migrantes y en condiciones de vulnerabilidad”, en VII Jornadas de Sociología de la UNLP, La Plata, Universidad Nacional de La Plata, Argentina.

Malegarie, J. y D. Lanzetta (2013): "La escuela ante la gestión de la diversidad", en X Jornadas de Sociología, Buenos Aires, Facultad de Ciencias Sociales. 
Universidad de Buenos Aires.

Marradi, A., N. Archenti y J. Piovani (2012): Metodología de las ciencias sociales, Buenos Aires, Cengage.

Mora, M. (2002): "La teoría de las representaciones sociales de Serge Moscovici”, Revista Athenea Digital, 2, pp. 1-25.

Moscovici, S. (1986): Psicología social, Barcelona, Paidós.

Novaro, G. (2011): La interculturalidad en debate. Experiencias formativas y procesos de identificación en niños indígenas y migrantes, Buenos Aires, Biblos.

Novick, S. (2010): Migraciones y Mercosur: una relación inconclusa, Buenos Aires, Catálogos.

Rodríguez Osuna, J. (1994): "La muestra: teoría y aplicación”, en M. García Ferrando, J. Ibáñez y F. Alvira, comp., El análisis de la realidad social. Métodos y Técnicas de investigación, Madrid, Alianza, pp. 445484.

Sabido Ramos, O. (2012): El cuerpo como recurso de sentido en la construcción del extraño. Una perspectiva sociológica, México D. F., Sequitur - UAM-Azcapotzalco.

Segato, R. (2007): La nación y sus otros. Raza, etnicidad y diversidad religiosa en tiempos de políticas de la identidad, Buenos Aires, Prometeo.
Walsh, C. (2005): La interculturalidad en la educación, Lima, Ministerio de Educación.

\section{Notas:}

1Decidimos circunscribir el análisis de las representaciones sociales al caso de la comunidad boliviana, puesto que a partir de la necesidad de acotar la extensión del artículo nos era imposible presentar los resultados para todas las nacionalidades. Sin embargo, el conocimiento previo sobre la temática nos condujo a tal elección no sólo porque la comunidad boliviana es uno de los grupos de larga tradición migratoria hacia Argentina, sino también porque es una de las comunidades de extranjeros de mayor presencia poblacional según el censo 2010.

2El censo 2010 registró que, del total de extranjeros en Argentina, el 41,1\% se concentra en el Gran Buenos Aires y el 21,1\% en la Ciudad Autónoma de Buenos Aires. Las comunas con mayor proporción de población extranjera con respecto a la población total de la misma son: Comuna $1(24,7 \%)$, Comuna 8 $(23,4 \%)$ y Comuna $7(18,6 \%)$. En la Comuna 1 , conformada por los barrios de Retiro, San Nicolás, Puerto Madero, San Telmo y Monserrat, de un total de 50.948 extranjeros censados, el $24,2 \%$ son paraguayos, $19,6 \%$ peruanos, el $11 \%$ bolivianos y sólo el 3,4\% chilenos. Es destacable el porcentaje de no nativos de origen europeo, que se sitúa en un 13, 5\%. En la Comuna 8, de la que forman parte los barrios de Villa Soldati, Villa Riachuelo y Villa Lugano, de 43.742 extranjeros, se destaca el elevado porcentaje de población originaria de Bolivia llegando a un $46,6 \%$ del 
total de extranjeros. En segundo orden se observa un $37,9 \%$ de personas de origen paraguayo, un $6,2 \%$ de no nativos de origen europeo, y una proporción de origen peruano del 5,2\%.

${ }^{3}$ Se quita la referencia para no perder el anonimato del artículo

${ }^{4}$ Es preciso aclarar que el sistema de selección de las unidades muestrales para el presente estudio se encuentra definido por un tipo de muestreo no probabilístico, menos preciso frente a aquellos denominados probabilísticos, y por ende acotado a una caracterización de la muestra sin poder hacer extensibles los resultados a un universo mayor. El recurso a este método viene dado, principalmente, por los costes que implica optar por uno u otro en términos de los recursos disponibles para llevarlo a cabo. En este punto, reconocemos la limitación en poder hacer estimaciones y de la posibilidad de medir errores de muestreo, por lo que los resultados de la encuesta carecen de fiabilidad en términos estadísticos, lo que no quita que guarde significatividad teórica. Otra cuestión a señalar es que no se ha buscado establecer covariación de los distintos aspectos del fenómeno bajo estudio, sino una descripción de la muestra a través de distribuciones univariadas del mismo. Ello se debe al carácter exploratorio de los recursos metodológicos implementados a tal efecto. Así, la combinación de un enfoque cuantitativo como estrategia de acceso a la población de estudiantes de escuelas públicas de Villa Lugano, junto con implementar el método de la Teoría Fundamentada como guía para el análisis de las respuestas a las preguntas de respuesta abierta (de libre asociación, debiendo responder los/as encues- tados con una sola palabra), se orienta a la construcción del dato en términos de establecer dimensiones constituidas a partir de núcleos representacionales que emergen a partir de la codificación realizada.

5Una cuestión no menor, es el hecho que, al trabajar con menores de edad, se debió proceder desde un inicio, es decir, desde el momento mismo de establecer el contacto con las escuelas para ingresar al campo a fin de realizar el relevamiento de información, respetando procedimientos definidos por tal circunstancia. Primeramente, se recurrió al pedido de aprobación al Comité de Ética del Instituto de Investigaciones Gino Germani, y bajo el consentimiento de dicha institución, nota de autorización mediante, se hizo llegar la misma a cada una de las escuelas que accedieron a evaluar la propuesta para que realizáramos el relevamiento, junto con la presentación de una copia del proyecto de investigación y del instrumento de registro. Una vez aprobada por los directivos e inspectores de las escuelas, se accedió a las mismas presentando una carta de aval y agradecimiento firmada por autoridades del instituto de investigaciones consultado por nuestro equipo para tal fin.

${ }^{6}$ La Teoría Fundamentada (Grounded Theory) es una estrategia de investigación a partir de la cual se busca promover la generación de teoría a partir de los datos. 